Acknowledgement

Bella Ben-Gershon, BA, provided information on the emergency preparedness programme.

\section{References}

Al-Krenawi, A. (1999) Explanation of mental health symptoms by the Bedouin-Arabs of the N egev. International Journal of Social Psychiatry, 45, 56-64.

Al-Krenawi, A. \& Graham, J. R. (1999) Gender and biomedical/ traditional mental health utilization among the Bedouin-Arabs of the N egev. Culture, Medicine and Psychiatry, 23, 219-243.

Apter, A. (1998) Child psychiatry in Israel - towards the millennium. Israel Journal of Psychiatry, 35, 251-252.

Bilu, Y. \& W Witztum, E. (1997) The mental health of Jews inside and outside Israel. In Ethnicity, Immigration, and Psychopathology (eds I. Al-Issa \& M. Tousignant), pp. 235-256. N ew York: Plenum

Central Bureau of Statistics (2002) Statistical Abstract 2001. Jerusalem: G overnment of Israel.

Department of Information and Evaluation (2002) Mental Health in Israel. Statistical Annual 2002. Jerusalem: Ministry of Israel.

Feinson, M. C., Lerner, Y., Levinson, D., et al (1997) Ambulatory mental health treatment under universal coverage: policy insights from Israel. M ilbank Quarterly, 75, 235-260.

Greenberg, D. \& Witztum, E. (2001) Sanity and Sanctity. N ew Haven, CT: Yale University Press.
Kark, J. D., Goldman, S. \& Epstein, L. (1995) Iraqi missile attacks on Israel. The association of mortality with a life-threatening stressor. Journal of the American Medical Association, 273, 1208-1210.

Laor, N., Wolmer, L., Mayes, L. C., et al (1996) Israeli preschoolers under SCUD missile attacks. A developmental perspective on risk-modifying factors. Archives of General Psychiatry, 53, 416-423.

Levav, I. (1998) Individuals under conditions of maximum adversity. In Stress, Adversity and Psychopathology (ed. B. P. Dohrenwend). N ew York: 0 xford U niversity Press.

$\mathrm{N}$ akar, S., Kahan, E., N ir, T., et al (1996) The influence of SCUD missile attacks on the utilization of ambulatory services in a family practice. Medicine, Conflict, and Survival, 12, 149-153.

Patel, V. (2002) Research Environment in Developing Countries: Making It Happen. Cape Town: World Health O rganization.

Solomon, Z. \& Prager, E. (1992) Elderly Holocaust survivors during the Persian Gulf War: a study of psychological distress. American Journal of Psychiatry, 149, 1707-1710.

Solomon, Z., Laor, N., Weiler, D., et al (1993) The psychological impact of the Gulf War: a study of acute stress in Israeli evacuees. Archives of General Psychiatry, 50, 320 321.

Soskolne, V., Baras, M., Palti, H., et al (1996) Exposure to missile attacks: the impact of the Persian Gulf War on physical health behaviors and psychological distress in high and low risk areas in Israel. Social Science and Medicine, 42, 1039-1047.

\title{
Mental health services in Albania
}

\author{
Anastas Suli ${ }^{1}$, Ledia Lazëri² and Livia Nano ${ }^{3}$
}

\begin{abstract}
${ }^{1}$ Head of the Psychiatric Department of the University Hospital Centre, 'Mother Teresa', Tirana, and Chairman of the National Steering Committee for Mental Health

${ }^{2}$ National Professional Officer at the WHO Country Office, Albania, and Coordinator of the Albanian

Development Centre for Mental Health, email ledial@who-albania.org

${ }^{3}$ Psychologist at the Albanian Development Centre for Mental Health
\end{abstract}

The care system remains prey to financial and regulatory rigidity. The system is still highly centralised and lacks a focus on the social welfare of citizens. Decentralisation and open governance within a framework of comprehensive reform are prerequisites for better services.
Ibania, situated in the western Balkans, has an area of $28748 \mathrm{~km}^{2}$ and a population of 3069275 (year 2001), almost one-third of whom are aged 0-14 years. Life expectancy is estimated to be 70.4 years for both sexes (World Health $O$ rganization, 2003a). According to the World Health O rganization's classification, Albania is a country with low child and low adult mortality rates. The nation's total expenditure on health in 2001 amounted to $3.7 \%$ of gross domestic product.

For more than a decade Albania has been undergoing a transitional process of democratisation of its so ciety and decentralisation of its systems, including systems of care in general. H ow ever, its relatively recent totalitarian past had created a culture of lack of community initiative, participation and decision-making, and the care system remains prey to financial and regulatory rigidity. The system is still highly centralised and lacks a focus on the social welfare of citizens. Decentralisation and open governance within a framew ork of comprehensive reform are prerequisites for better services. Furthermore, any intervention to improve the health system will need to take into account the fact that Albania is not a rich country and health is not the top priority when it comes to the allocation of national resources.

\section{Education in psychiatry}

Formal psychiatric education is provided by the only university department of psychiatry in the country; it is part of the Faculty of Medicine of the U niversity of Tirana. Education in psychiatry has had to be transformed in order for it to meet international standards. W hile psychiatry constitutes $1.4 \%$ of the overall training hours in the university curriculum for medical doctors, in 1994 postgraduate psychiatric education was extended from 9 months of internship to 4 years of residency in the university clinic.

Residents annually discuss their training plan with their supervisors. They attend to and follow clinical cases in their charge. The professional qualification for psychiatrists involves several yearly examinations across the entire residency period, and one final examination (oral and written). While the curriculum offers satisfactory training in biological psychiatry, it is difficult to train young residents properly in the psychosocial aspects of practice, as there are few supervisors with sufficient experience and 
knowledge in this area. Psychotherapy is taught only theoretically - there is no opportunity for practice and supervision - and psychosocial rehabilitation is missing from formal residency training because the university clinic has no facilities for it.

A curriculum for a residency in child and adolescent psychiatry has recently been approved. This means that the academic year 2004-05 will mark the initiation of a 4year programme that will cover general paediatrics, neuropaediatrics, general psychiatry, and child and adolescent psychiatry. It is a step forward in giving to the population better access to more appropriate services.

There are no formal specialisation courses for psychiatric nurses or for clinical social workers, although psychology students in the last year of their undergraduate studies can choose to specialise in clinical psychology or organisational psychology. There is no formal training for occupational therapists.

W ith an increasing awareness of the need for continuing medical education, including in psychiatry, there are formal negotiations going on between the Ministry of $\mathrm{H}$ ealth and the Ministry of Education in order to establish a responsible body.

\section{Clinical practice and services}

Clinical practice in psychiatry in Albania is exceedingly demanding because so few resources are dedicated to mental illness. For example, within community mental health facilities for children and adults (psychiatric wards in general hospitals, ambulatory clinics, community mental health centres, day centres), there are, nationally, 69 neuropsychiatrists (who have a combined neurologypsychiatry postgraduate qualification, which was abolished in 1974) and psychiatrists (2.2 per 100000 population), of whom $54 \%$ are psychiatrists; 130 nurses (4.2 per $100000) ; 6$ psychologists $(0.2$ per 100000$) ; 12$ social workers ( 0.4 per 100000$)$; and 8 occupational therapists $(0.3$ per 100000$)$. These figures suggest that psychiatrists (and other professionals) working in ambulatory settings will confront a demand that is impossible to respond to properly in either quantitative or qualitative terms. Except where community mental health centres are already established, the ambulatory clinics are staffed by only one psychiatrist and one nurse, who mostly do diagnostic work and prescribe psychotropic drugs. Psychiatric home care is seldom supported, and visits to a patient's home are made (if at all) only when the patient is not compliant with aspects of psychiatric care.

Albania's in-patient facilities comprise two psychiatric hospitals (Elbasan and Vlora) and two psychiatric wards within general hospitals (Tirana and Shkodra). Except for some administrative/budgetary differences, the approach to service provision is the same for these psychiatric hospitals and wards. The hospitals and wards have a total of 840 beds. This is not a very low figure for the country's population but because half the beds are used for long-stay patients the demand for in-patient services cannot be met.

The two mental hospitals in Elbasan and Vlora have 12 psychiatrists, 93 nurses and 5 occupational therapists.
There are no psychologists or social workers at these hospitals.

Psychiatric hospital care involves diagnostic work and free medication - there are few activities available to patients. There is little in the way of rehabilitative work, as it would require a budget and human resources but at present is not a priority.

\section{Legislation}

The Albanian Parliament approved the Mental Health Act in 1996. It provides a framework for compulsory examinations, admissions and treatment, but pays little attention to the establishment of comprehensive, deinstitutionalised services. However, the main problem of the Act is in its implementation. Lack of community services means that institutions continue to be used to segregate people with a mental illness. Efforts are being made to redress the situation, and to build up supportive alternatives, through the dratting of a national mental health policy.

\section{Developments in mental health}

M any actions were taken during the 1990s by international organisations to improve aspects of Albania's psychiatric services, including training and education, day centres and the rehabilitation of institutionalised patients. U nfortunately, these initiatives had little long-term effect. This brought the realisation that it is essential to involve the national authorities in any such work, as this will improve the chances of implementing a break with tradition and establishing new practices. This would be true anyw here in the world, but is particularly pertinent to the Albanian case, where systems are still managed centrally and so where any important, radical change needs the commitment and influence of central autho rities in addition to the initiative and will of local professionals or community groups. Thus, based on the lessons learnt, national professionals have more recently drawn on international expertise in an effort to establish a reform process oriented towards the delivery of comprehensive community mental health services by multi-disciplinary teams.

In 1999 the Ministry of $\mathrm{H}$ ealth embraced a proposal by the World $\mathrm{H}$ ealth $\mathrm{O}$ rganization for a comprehensive reform of the entire psychiatric system. This was made the responsibility of a national organisation when, in 2000 , the Minister of $\mathrm{H}$ ealth established the $\mathrm{N}$ ational Steering Committee for Mental H ealth. Moreover, the Committee was given the powers necessary to implement the changes required. With technical input from the World Health $O$ rganization, the main focus of the Committee has been on elaborating the mental health po licy referred to above. This should provide the political framework for change. The Policy for Mental Health Services D evelopment in Albania was approved by the Minister of $\mathrm{H}$ ealth in March 2003. It defines the national goal as the 'establishment and development of a national community mental health care system', and describes two main tools to reach the goal: the downsizing of the psychiatric hospitals and the decentralisation of services.
With an increasing awareness of the need for continuing medical education, including in psychiatry, there are formal negotiations going on between the Ministry of Health and the Ministry of Education in order to establish a responsible body. 
As mandated by the policy document, the $\mathrm{N}$ ational Steering Committee is currently elaborating a strategy for the implementation of the mental health policy, assisted by the World Health 0 rganization.

In addition, pilot projects are now being run to show the feasibility and benefits of community-based mental health care.

Considering all the above, there are at present better chances than ever before of achieving comprehensive and accessible mental health services in Albania.
References and sources

Institute of Statistics (2003) 1993-2001 Statistical Yearbook. Tirana: IN STAT.

$\mathrm{N}$ ational Steering Committee for Mental Health (2003) Policy for M ental Health Services Development in Albania.

World Health O rganization (2003a) Atlas: Country Profiles on M ental Health Resources 2001. Geneva: WHO.

World Health Organization (2003b) The World Health Report 2003. Geneva: WHO.

World Health O rganization Country O ffice Albania (2003) M onitoring M ental Health Systems and Services: Case Albania, circulated paper. Geneva: WHO

\section{Since ethics involves a set of principles, doctors are tempted to seek answers in law or in professional codes of ethics when they encounter problems. These approaches do not necessarily solve problems - certainly not in Africa.}

\title{
SPECIAL PAPER
}

\section{Current ethical issues for African psychiatry}

\author{
Tuviah Zabow
}

Professor, Department of Psychiatry and Mental Health, University of Cape Town, South Africa, email zabowt@curie.uct.ac.za

ne of the challenges of medical practice is to resolve the conflicts that arise when a professional is required to choose between competing ethical principles. This is especially true in psychiatry. The answers to ethical issues are not necessarily right or wrong. Ethics in psychiatry is complex, and numerous dilemmas may confuse the picture. Clinicians and researchers bring their own values to the scenario, but they must also deal with the values of their colleagues and their patients, as well as those of the wider (multicultural) community. These conflicts traditionally concern confidentiality, informed consent, involuntary hospitalisation, the right to treatment, the right to refuse treatment and the regulation of psychiatric research, among others. These are universally encountered but present differently across the regions of the world.

\section{Principles of the debate and the African perspective}

The principles usually addressed in bioethics debates are particularly applicable to the practice of psychiatry in Africa. For example, the principle of autonomy is prominent in the changes from tribal or colonial dominance to democratic governance. Human dignity and respect, and the principles of beneficence and non-maleficence require consideration in the discussion. Patient confidentiality needs to addressed in professional training and the formulation of policy. Respect for the patient is shown in the efforts made to restore or maximise the mentally ill patient's competence or other capacities. The more we aim to restore capacity, the nearer we come to the ideal of respect for persons. The principle of justice is probably the most important, however, in light of the scarcity of resources.

Since ethics involves a set of principles, doctors are tempted to seek answers in law or in professional codes of ethics when they encounter problems. These approaches do not necessarily solve problems - certainly not in Africa.

The themes are common but some of the ethical issues for African psychiatry are different from those in developed countries and the approach needs to be somewhat less Western. The emphasis in Africa should be on the ethical educational input and general sensitisation, on ongoing training and thus on the circumstances of professional practice. Public sanction and support are essential, as are the involvement of the community and concern for the safety and well-being of its members. Indigenous healers (as an example of a cultural factor) must be carefully considered. Their involvement is being formalised in many countries and is a topic of discussion in itself.

What of international standards? Although universal principles are accepted, care must be taken to avoid the trap of imposing 'their' views and solutions on 'our' situations. The Madrid Declaration drawn up by the World Psychiatric Association attempts to meet this need for its smaller member countries. The 2000 revision of the H elsinki Declaration recognises the vulnerability of developing countries with a poor resource base in research.

The essence of an ethical dilemma is that there is no simple correct solution. Africa has raised key ethical issues, from apartheid, genocide and pandemic illnesses to the role of women, AIDS, poverty and tribal wars. All these have had an influence on the mental health of its populations. Certain issues need to be focused on in an approach to the dynamic area of ethics in Africa - a large and complex continent. These are discussed below. 